\title{
Characterization of dissolved organic matter in a dynamic membrane bioreactor for wastewater treatment
}

\author{
ZHANG YaLei ${ }^{1}$, ZHANG Hai ${ }^{1,2}$, CHU HuaQiang $^{1 *}$, ZHOU XueFei $^{1} \&$ ZHAO YangYing ${ }^{1}$ \\ ${ }^{1}$ State Key Laboratory of Pollution Control and Resource Reuse, School of Environmental Science and Engineering, Tongji University, Shanghai \\ 200092, China; \\ ${ }^{2}$ Modern Agricultural Science \& Engineering Institute, Tongji University, Shanghai 200092, China
}

Received July 20, 2012; accepted November 23, 2012; published online April 1, 2013

\begin{abstract}
This paper systematically examined the characteristics of dissolved organic matter (DOM) in a dynamic membrane bioreactor (DMBR) for municipal wastewater with a laboratory-scale continuous-flow device. Experimental results showed that the system performed excellent pollutants' removal efficiencies. The increase of trans-membrane pressure (TMP) for the dynamic membrane (DM) could be divided into three stages, i.e., zero increase stage, slow increase stage and abrupt rise stage. The maximal fouling rate of the $\mathrm{DM}$ reached to $4.34 \mathrm{kPa} / \mathrm{h}$ in abrupt rise stage. It was observed that the polysaccharides (PS) concentration of DOM samples gradually increased from the anaerobic zone to the aerobic zone in sequence, but the proteins (PN) concentration performed an opposite trend. The DM could retain a small part of the large molecular substances $(>10 \mathrm{kDa})$ in the aerobic zone. Two particular fluorescence peaks appeared in the anaerobic zone and in the anoxic zone were also found in the effluent, which illustrated the dynamic cake layer closed to the stainless steel mesh might induce an anaerobic/anoxic micro environment. Based on the three-dimensional excitation-emission matrix (EEM) fluorescence spectroscopy analysis, aromatic proteins, aromatic proteinlike substance, fulvic acid-like substances and soluble microbial by-product-like materials could be biodegraded effectively in the DMBR, and the DM could partly remove the humic acid-like substances and soluble microbial by-product-like materials.
\end{abstract}

dissolved organic matters, dynamic membrane bioreactor, three-dimensional excitation-emission matrix fluorescence spectroscopy, membrane fouling, wastewater treatment

Citation: Zhang Y L, Zhang H, Chu H Q, et al. Characterization of dissolved organic matter in a dynamic membrane bioreactor for wastewater treatment. Chin Sci Bull, 2013, 58: 1717-1724, doi: 10.1007/s11434-013-5710-9

The conventional membrane bioreactor (CMBR) equipped with micro-filtration membrane or ultra-filtration membrane represents an important development in the wastewater treatment and reclamation technology, but its widespread application is hampered by the high initial cost of membrane module, high energy consumption and difficult membrane fouling control [1-3]. The dynamic membrane (DM) is formed on the big aperture support mesh by the filtered solution containing fine particles [4]. Compared with the CMBR, the dynamic membrane reactor (DMBR) is advantageous in high effluent flux, easy back washing, low energy consumption and low cost of membrane module [5].

*Corresponding author (email: chq123zl@hotmail.com)
DOM originated from biological wastewater treatment process contains different organic compounds, such as carbohydrates, proteins, fulvic acid and humic acid [6,7]. Another definition is that the DOM is a heterogeneous mixture of aromatic and aliphatic organic compounds containing oxygen, nitrogen, and sulfur functional groups (e.g., carboxyl, phenol, enol, alcohol, carbonyl, amide, and thiol) [8]. DOM played an important role in membrane fouling process [9-11], and numerous efforts have been made to study the influence of DOM in mixed liquors on the membrane performance [12-14]. Kimura et al. [3] and Liang et al. [15] reported that DOM was the key membrane foulants and especially responsible for the long-term irreversible fouling of membranes. Protein-like substances in DOM was the 
dominant fluorescence substances in membrane foulants due to the membrane retention capacity [8]. Meanwhile, Liang and Song [16] found that the aquatic humic acid substances were the major component of DOM to membrane fouling. As the DMBR being a new wastewater treatment process, the information about the mutual influences of the DOM in anaerobic, anoxic and aerobic zone on the DMBR operation is limited. It is essential to study the characteristics of DOM in each reactor zone more comprehensively, as well as its potential for the dynamic membrane fouling.

Therefore, the purpose of this study is to obtain more comprehensive information on DOM in the anaerobic, anoxic and aerobic zone and their influences on the performance of the DMBR. Analytical methods including photometric quantity analysis method, gel filtration chromatography (GFC) and three-dimensional excitation-emission matrix (EEM) fluorescence spectroscopy were applied to gain insights into the characterization of the DOM samples in the DMBR. Furthermore, the effect of DOM on the DM fouling is also analyzed.

\section{Materials and methods}

\subsection{Experimental setup}

The DMBR with a total effective volume of $20 \mathrm{~L}$ consisted of three parts, i.e., anaerobic zone $(5 \mathrm{~L})$, anoxic zone $(5 \mathrm{~L})$ and aerobic zone $(10 \mathrm{~L})$ in sequence, as shown in Figure 1. The anaerobic environment was created by a water seal on the top of the anaerobic zone. The flat sheet DM module used a stainless steel mesh with an equivalent aperture of $75 \mu \mathrm{m}$ as the support layer, and its effective filtration area was $0.036 \mathrm{~m}^{2}$. The configuration of DM support module was referenced to $\mathrm{Chu}$ et al. [5]. A synthetic wastewater recipe simulating real domestic sewage was adopted. The synthetic wastewater was made by adding $150 \mathrm{mg} / \mathrm{L}$ glucose, $80 \mathrm{mg} / \mathrm{L}$ sodium acetate, $150 \mathrm{mg} / \mathrm{L}$ reptone, $80 \mathrm{mg} / \mathrm{L}$ $\mathrm{NH}_{4} \mathrm{Cl}$ and $26 \mathrm{mg} / \mathrm{L} \mathrm{KH}_{2} \mathrm{PO}_{4}$. Required trace metals provided to the bioreactor was $10.6 \mathrm{mg} / \mathrm{L} \mathrm{CaCl}, 20 \mathrm{mg} / \mathrm{L}$ $\mathrm{MgSO}_{4} \cdot 7 \mathrm{H}_{2} \mathrm{O}, 3 \mathrm{mg} / \mathrm{L}$ EDTA-Na, $0.45 \mathrm{mg} / \mathrm{L} \mathrm{FeCl}_{3} \cdot 6 \mathrm{H}_{2} \mathrm{O}$, $0.036 \mathrm{mg} / \mathrm{L} \mathrm{MnCl}{ }_{2} \cdot 6 \mathrm{H}_{2} \mathrm{O}, 0.045 \mathrm{mg} / \mathrm{L} \mathrm{H}_{3} \mathrm{BO}_{3}, 0.036 \mathrm{mg} / \mathrm{L}$ $\mathrm{ZnSO}_{4} \cdot 7 \mathrm{H}_{2} \mathrm{O}, 0.009 \mathrm{mg} / \mathrm{L} \mathrm{CuSO}{ }_{4} \cdot 5 \mathrm{H}_{2} \mathrm{O}, 0.054 \mathrm{mg} / \mathrm{L} \mathrm{KI}$ and $80 \mathrm{mg} / \mathrm{L} \mathrm{NaHCO}_{3}$ used as a buffer to adjust the influent $\mathrm{pH}$. The dynamic membrane effluent was withdrawn by a peristaltic pump connected to the support module. A mercury manometer was fixed between the support module and the permeate pump to measure the TMP of the DM. Air was supplied through the pinhole aerator pipe below the membrane module to induce a cross-flow near the dynamic membrane surfaces and provide oxygen for the microorganisms in the reactor.

\subsection{Operation methods}

Continuous operation of the DMBR was carried out under

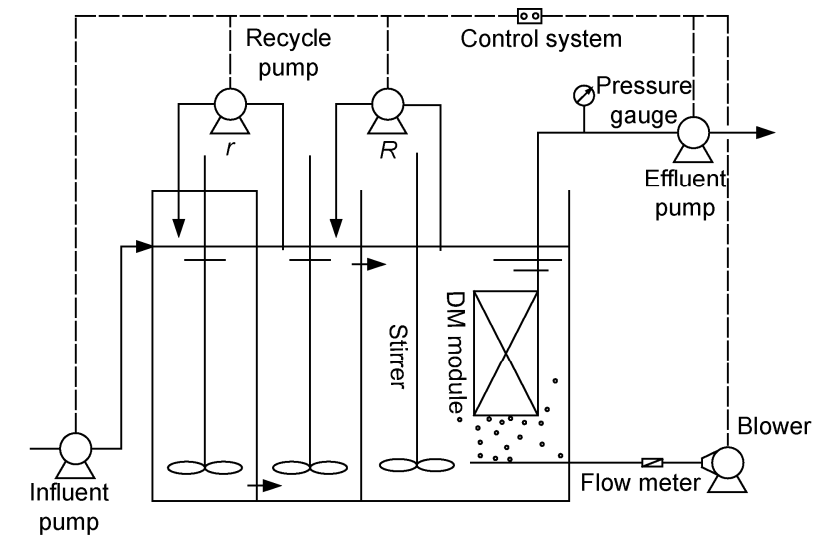

Figure 1 Diagram of the DMBR.

the filtration flux of $50 \mathrm{~L} /\left(\mathrm{m}^{2} \mathrm{~h}\right)$. Mixed liquors of the aerobic zone and the anoxic zone were recycled to the anoxic zone (recirculation $R$ ) and the anaerobic zone (recirculation $r$ ), and the recycle rates were controlled at 2 times and 1 times of the influent flow rate, respectively. The sludge retention time (SRT) of the BDMR was maintained at $40 \mathrm{~d}$ by discharging the mixed liquor from the bioreactor daily. The dissolved oxygen (DO) concentration of the anaerobic zone, anoxic zone and aerobic zone was in the range of $<0.2 \mathrm{mg} / \mathrm{L}$, $0.3 \mathrm{mg} / \mathrm{L}$ and $1-2 \mathrm{mg} / \mathrm{L}$, respectively.

\subsection{Analytical methods}

(1) Samples pretreatment. The water phase of the activated sludge originating from the three zones of the DMBR were centrifuged $(1500 \mathrm{r} / \mathrm{min}, 10 \mathrm{~min})$ at $4^{\circ} \mathrm{C}$ followed by the filtration through $0.45 \mu \mathrm{m}$ membrane. The influent and the DM effluent were filtrated through $0.45 \mu \mathrm{m}$ membrane. All the filtrates were used as the samples for DOM analysis.

(2) Analytical items. A luminescence spectrometry (F4500 FL spectrophotometer, Hitachi, Japan) was employed to conduct the three-dimensional EEM spectra of the all DOM samples. The software origin 8.0 (OriginLab Corporation, USA) and surfer 8.0 (Golden Software, USA) were used to process the EEM data. The filtrates of DOM samples were fractionated by a GFC analyzer, which consisted of a TSK G4000SW type gel column (TOSOH Corporation, Japan), a liquid chromatography spectrometer (LC-10ATVP, SHIMADZU, Japan) and a refractive index detector (RID10A). Polyethylene glycols with molecular weight (MW) of 1215, 274.4, 128, 11.84 and 194 kDa (Merck Corporation, Germany) were used as standards for calibration. The total EPS dissolved in the supernatant was expressed as the sum of carbohydrates and proteins. A phenol-sulfuric acid method was used to quantify polysaccharides with a glucose standard [17]. Protein content was determined by the modified Lowry method with bovine serum albumin (BSA) as the standard [18].

Measurements of chemical oxygen demand (COD), total 
nitrogen (TN), total phosphorus (TP), ammonia $\left(\mathrm{NH}_{3}-\mathrm{N}\right)$, mixed liquor suspended solids (MLSS) and mixed liquor volatile suspended solids (MLVSS) in the reactor were performed according to the Chinese NEPA standard methods [19]. The $\mathrm{pH}$ was determined by a pH meter (PHS-3C, China). The dissolved oxygen (DO) concentration was measured with a DO meter (Model HQ30d, HACH, USA). The filtration flux of the dynamic membrane was measured with volumetric method.

\section{Results and discussion}

\subsection{DMBR performance}

Table 1 summarizes the regular pollutant removal efficiency in the steady operation period of the DMBR. It can be seen that the removals of pollutants were very effective by the DMBR, especially TP removal. The poly-phosphate accumulating organisms had a preferably anaerobic environment to release $\mathrm{P}$ in the anaerobic zone of the DMBR, and the TP concentration in supernatant of the anaerobic zone reached to around $20 \mathrm{mg} / \mathrm{L}$, which was much greater than that in the influent. Therefore, the excessive P uptake could be achieved effectively by the poly-phosphate accumulating organisms in the aerobic zone after the completion P release in anaerobic environment. The average $C: N: P$ ratio of $100: 10.6$ : 0.98 of synthetic wastewater and the average volumetric load of $1.08 \mathrm{~kg} \mathrm{COD} /\left(\mathrm{m}^{3} \mathrm{~d}\right)$ used in this research might also facilitate the TP removal [20].

The variations of DM flux and TMP in an operation cycle are shown in Figure 2. Many studies have focused on the two-stage TMP increase of the membrane filtration process, i.e., a slow and gradual increase followed by an abrupt rise in the TMP [21-23]. According to the Figure 2, the TMP increase of the DM was divided into three stages, i.e., zero increase stage, slow increase stage and abrupt rise stage, which is similar with the findings reported by Zhang et al. [24]. The TMP increase rate per unit time of DM is directly related to the rate of membrane fouling. It can be seen that the TMP always kept at $0 \mathrm{kPa}$ during the zero increase stage of the DM filtration process, which lasted approximately $50 \mathrm{~h}$. The possible reason for this phenomenon might be that the cake layer deposited on membrane surface was very thin $(<1 \mathrm{~mm})$ at the initial filtration stage. Following closely, the

Table 1 Characteristics of the influent and effluent in the DMBR ${ }^{\mathrm{a})}$

\begin{tabular}{lccc}
\hline \multicolumn{1}{c}{ Items } & Influent & Effluent & $\begin{array}{c}\text { Removal efficiency } \\
(\%)\end{array}$ \\
\hline $\mathrm{COD}(\mathrm{mg} / \mathrm{L})$ & $375.8 \pm 35.5$ & $37.1 \pm 15.8$ & $90.0 \pm 0.04$ \\
$\mathrm{TN}(\mathrm{mg} / \mathrm{L})$ & $39.9 \pm 5.2$ & $10.1 \pm 1.8$ & $72.9 \pm 0.04$ \\
$\mathrm{TP}(\mathrm{mg} / \mathrm{L})$ & $3.7 \pm 0.5$ & $0.05 \pm 0.12$ & $98.8 \pm 0.03$ \\
$\mathrm{NH}_{3}-\mathrm{N}(\mathrm{mg} / \mathrm{L})$ & $23.9 \pm 1.1$ & $0.7 \pm 1.0$ & $96.7 \pm 0.05$ \\
\hline
\end{tabular}

a) Values are given as mean value \pm standard deviation $(n=40)$.

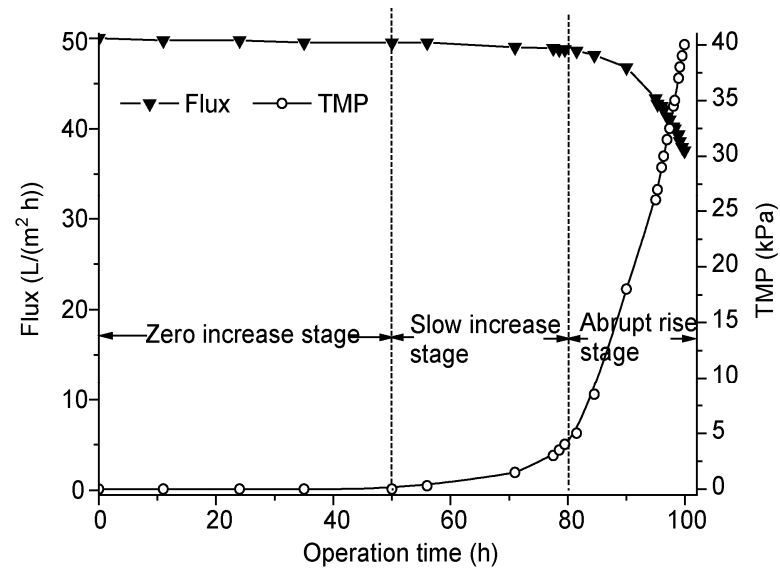

Figure 2 Variations of the flux and TMP with time in a DM filtration process.

TMP increased slowly and the average DM fouling rate was $0.16 \mathrm{kPa} / \mathrm{h}$ in this stage, which might result from the cake layer condensation and the porosity degression. Zhang et al. [24] also found that pore blocking could lead to the steady TMP rise in this stage. In the third stage, TMP increased rapidly from 5 to $40 \mathrm{kPa}$ in $20 \mathrm{~h}$ corresponding to the maximal fouling rate $4.34 \mathrm{kPa} / \mathrm{h}$, and the filtration flux of DM declined rapidly. The filtration process was terminated when the TMP reached $40 \mathrm{kPa}$ and the thickness of cake layer on support mesh surface was approximate $0.86 \mathrm{~cm}$. So the cake layer might contribute to the major filtration resistance of DM [25].

\subsection{EPS concentration in DOM}

EPS are complex mixture of macromolecular polyelectrolytes including polysaccharides, protein, humic compounds, and nucleic acids $[26,27]$. EPS, which are deemed to be the most significant biological factor responsible for membrane fouling [28], could be influenced by both the process design and the operational factors [29-31]. The variations of total EPS, PN and PS in DOM in the DMBR are shown in Figure 3(a). PN concentration decreased sharply while the concentration of PS gradually increased from the anaerobic zone to the anoxic zone and to the aerobic zone. The feeding carbon source originated from sodium acetate and glucose could be easily biodegradable. PS concentration was barely to $0.654 \pm$ $0.318 \mathrm{mg} / \mathrm{L}$ in anaerobic zone, and increased to $1.118 \pm 0.854$ $\mathrm{mg} / \mathrm{L}$ and $5.37 \pm 2.721 \mathrm{mg} / \mathrm{L}$ in the anoxic zone and the aerobic zone, respectively. Compared to the anoxic zone, the increased portion of PS in aerobic zone may be attributed to the release of microorganisms' secretion in the mixed liquid by the shear forces induced by aeration. Dvorak et al. [2] also found that the higher shear forces could cause activated sludge cells to produce more EPS to protect themselves from mechanical stress. During the treatment process, a part of PN had been degraded as essential energy for microorganism 

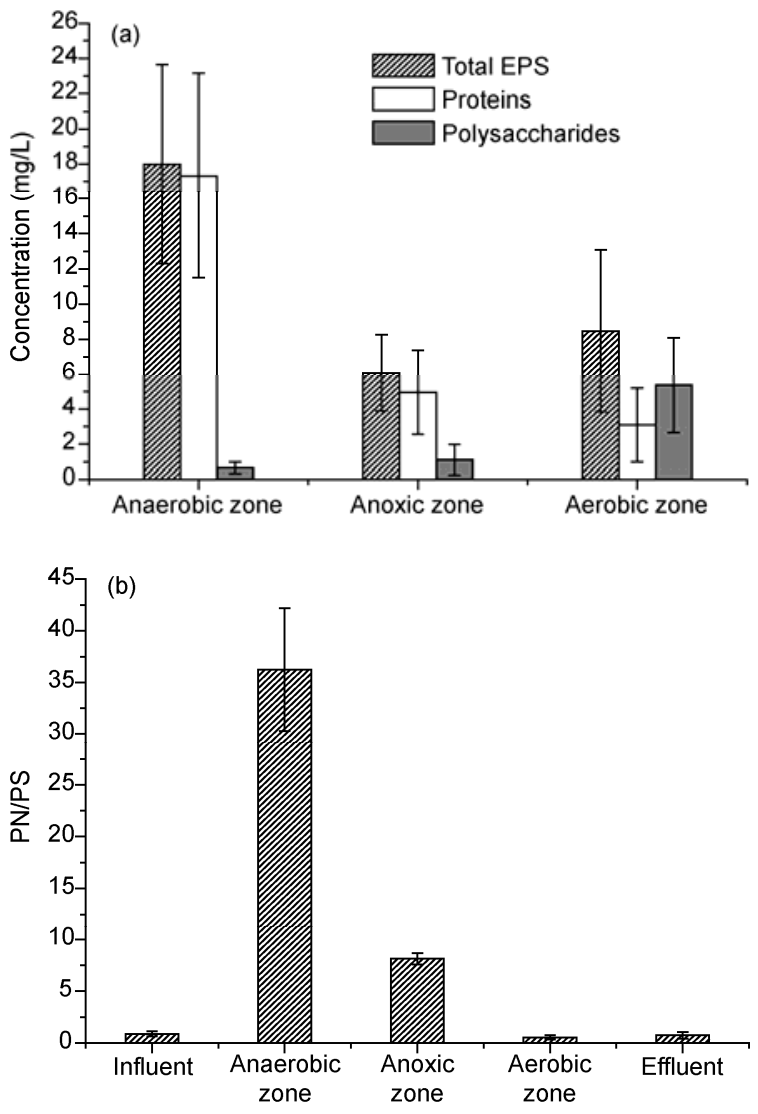

Figure 3 (a) EPS concentration in DOM; and (b) PN/PS ratio in DOM.

metabolism; meanwhile, EPS secreted by microorganism contained abundant protein-like substance, which might lead to the augmentation of PN concentration in DOM. The total EPS concentration in the aerobic zone was slightly higher than that in the anoxic zone, which was primarily influenced by the greater part of PS in the aerobic zone. So the aeration could induce more EPS released to the supernatant.

Some researchers have conducted on the membrane retention of soluble proteins and polysaccharides. Evenblij et al. [32] reported that the removal efficiencies of PN and PS by MBR were $15 \%$ and $40 \%$, respectively. However, Drews et al. [33] achieved $20 \%-70 \%$ retaining of proteins and $75 \%-100 \%$ retaining of carbohydrates in the MBR. Figure $3 b$ shows the variations of PN to PS (PN/PS) ratio in the DMBR of this research. The PN/PS ratio in the anaerobic zone reached as high as 36.23 , and then declined gradually. The highest PN/PS ratio in the anaerobic zone might be explained that the PS (sodium acetate and glucose) could be easily degraded while some protein-like substances of PN were non-degradable by the microorganisms. The average ratio of PN/PS in the aerobic zone was slightly lower than that in the effluent, which might due to the significant retention of polysaccharides-like substances by the DM. In this research, the averaged PN retention and PS retention by DMBR was about at $70.2 \%$ and $79.6 \%$, respectively.

\subsection{Molecular weight (MW) distribution of DOM}

The macromolecules or biomacromolecules substances have been widely considered as a major factor resulting in membrane fouling [34-36]. The MW distribution patterns of DOM samples were measured by the GFC method [37,38], as shown in Figure 4. Four major peak clusters in the MW order of $522.7 \mathrm{kDa}, 32.5-52.6 \mathrm{kDa}, 391 \mathrm{Da}$ and $<100 \mathrm{Da}$ were observed in the influent. In the aerobic zone and the effluent, the third peak cluster with the MW of $391 \mathrm{Da}$ completely disappeared, and the peak cluster with the MW of $32.5-52.6 \mathrm{kDa}$ cluster notably decreased by about $20 \%$. It can be seen that the first peak cluster in the aerobic zone and the effluent was increased than that in the influent, which might be ascribed to the biodegradation of the large molecules into small molecules by microorganisms. Moreover, the peak cluster of MW 407.8 and $71.7 \mathrm{kDa}$ in the aerobic zone were higher than those in the effluent, which suggested that the DM could retain a little part of compounds with high molecular weight. The $M_{\mathrm{w}} / M_{\mathrm{n}}$ (weightaverage molecular weight/number-average molecular weight) of the influent, the aerobic zone and the effluent were $282.41,451.08$ and 480.21 , respectively. A low coefficient of $M_{\mathrm{w}} / M_{\mathrm{n}}$ indicated a narrow MW distribution of the organic substances, while soluble microbial product generated by microorganisms had a broad MW distribution [8]. So much more soluble microbial product existed in the aerobic zone than in the influent.

The percentage of size-fractionated MW was shown in Figure 5 to further elucidate the size fraction of all samples. The percentage of large molecules $>100 \mathrm{kDa}$ in the aerobic zone was the largest among the three tested samples. The microorganisms could secrete much EPS of strong bioactivity in the aerobic zone, which might directly contribute to the development of a cake layer and the increase of the TMP. From the aerobic zone to the effluent, the percentages of the molecules $>10 \mathrm{kDa}$ reduced which indicated that the DM could retain some part of large molecular substances. The macromolecular compounds can be rejected and used as substrates for microorganisms while the small-size ones

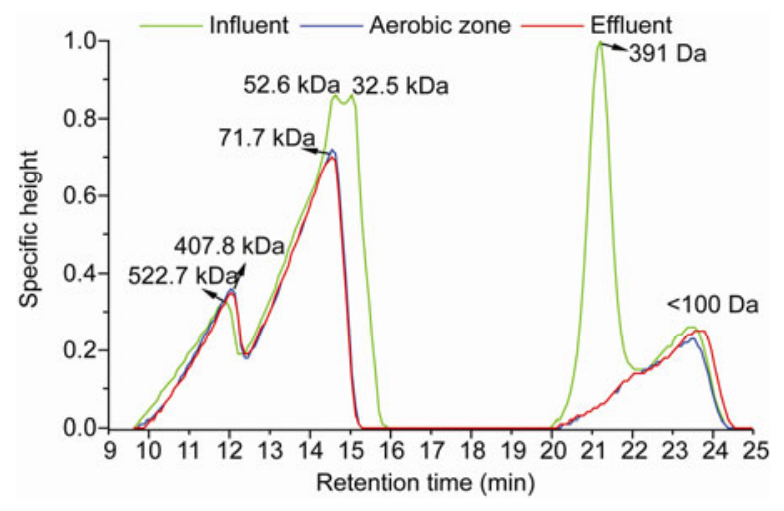

Figure 4 MW distributions of DOM samples. 


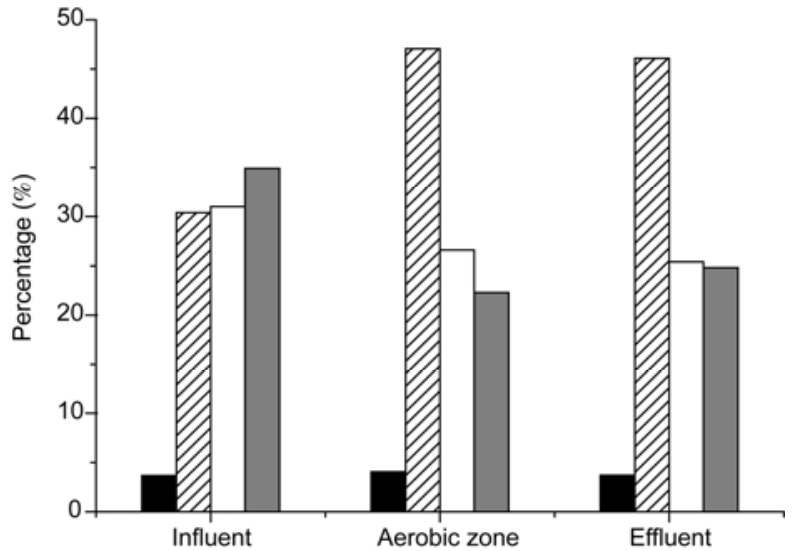

Figure 5 The percentage of size-fractionated MW of DOM samples. - $>1000 \mathrm{kDa}$, m $100-1000 \mathrm{kDa}, \square 10-100 \mathrm{kDa}, \square<10 \mathrm{kDa}$.

can be discharged along with permeate in the membrane filtration process $[39,40]$. However, compared with the micro/ ultra-filtration, the rejection degree by the DM was low. The proportions of matters with large molecular weight in supernatants and in effluents were almost identical [41].

\subsection{EEM fluorescence spectra analysis}

The three-dimensional EEM fluorescence spectra analysis can get spectral information about specific proteins (i.e., aromatic proteins and tryptophan proteins) and humic substances (i.e., humic acids and fulvic acids) of DOM samples [34]. The EEM fluorescence spectra of the DOM from the influent, the effluent and the aforementioned three zones in the DMBR are illustrated in Figure 6. The fluorescence intensities of the peaks in influent DOM (Figure 6(a)) were much more strongly than those in other samples (Figure 6(b)-(e)), and the peaks in the effluent DOM sample had the lowest fluorescence intensity, which is consistent with the results in Figure 3(a). The spectral peak $\mathrm{C}\left(E_{\mathrm{x}} / E_{\mathrm{m}}=230 /\right.$ $300 \mathrm{~nm}$ ) in the influent DOM sample disappeared in fluorescence spectra of other four samples. It also can be observed that there was no much change of the peak locations among the spectra of DOM samples from the three reaction zone in the DMBR (Figure 6(b)-(d)).

The fluorescence regional integration (FRI) method was employed to analyze the five excitation-emission regions in the EEM fluorescence spectra to better understand the information about DOM characteristics of samples [42]. Table 2 shows the EEM fluorescence spectral parameters of the DOM samples in the DMBR system. The peaks of the DOM obtained from all samples were different, which elucidated different compounds existed in the samples. According to the FRI, the regions I and II whose peaks at shorter excitation wavelengths $(<250 \mathrm{~nm})$ and shorter emission wavelengths $(<350 \mathrm{~nm})$ are related to aromatic proteins [42]. Peak $\mathrm{C}$ associated with the aromatic protein-like substance in the influent DOM disappeared from the anaerobic zone to the effluent. It indicates these aromatic protein-like substances which were easily biodegradable have been consumed by microorganisms in the anaerobic zone of the DMBR. The FRI of region III $\left(E_{\mathrm{x}} / E_{\mathrm{m}}\right.$ of $\left.200-250 />380 \mathrm{~nm}\right)$ represented fulvic acid-like substances [42]. A new peak (peak T) at the $E_{\mathrm{x}} / E_{\mathrm{m}}$ of $240 / 418-430 \mathrm{~nm}$ was appeared except in the influent samples. Therefore, certain specific fulvic acid-like organics might originate from the microorganism excretion or cell hydrolysis products. The Region IV, whose peaks at intermediate excitation wavelengths (250-280 nm) and shorter emission wavelengths $(<380 \mathrm{~nm})$, are related to soluble microbial by-product-like materials $[42,43]$. Two particular peaks at the $E_{\mathrm{x}} / E_{\mathrm{m}}$ of $270 / 348 \mathrm{~nm}$ and $280 / 310 \mathrm{~nm}$ appeared in the effluent, the anaerobic zone and the anoxic zone (Table 2). The thickness of the DM gradually increased ( $c a .15 \mathrm{~mm}$ at the most) as the filtration time extended, and the cake layer close to the stainless steel mesh might induce an anaerobic/anoxic micro environment. This phenomenon may facilitate the growth of anaerobic or anoxic microorganisms, and the soluble microbial by-productlike materials may enter the effluent by shear force during the filtration process. There is no obvious variations of the fluorescence intensity of peak $\mathrm{E}$ at the $E_{\mathrm{x}} / E_{\mathrm{m}}$ of $320 / 396-$ $400 \mathrm{~nm}$ (Region V) in all the samples. The location shift of the fluorescence peak means the considerable differences in chemical structure of DOM samples. Compared with the influent, almost all peaks of subsequent DOM samples were red-shifted $(2-6 \mathrm{~nm})$ and/or blue-shifted $(2-6 \mathrm{~nm})$ in a different degree. The red-shift and/or blue-shift of fluorescence peaks with proteins and humic substances implied the difference of compound structure in the DOM samples [44,45].

Based on the FRI method, the bar graph of the FRI percentage distribution is illustrated in Figure 7. It is interesting to note that the FRI percentage distributions of DOM samples were different. The FRI of Region V (approx.45.66\%) in the aerobic zone was larger than that of any other regions, which was approximate twice as much as that of the influent $(\sim 26.54 \%)$. It demonstrates that the humic acid-like substances is the dominant matter of DOM in the mixed liquid. Meanwhile, the FRI of Region V and Region IV in the effluent were less than that of the aerobic zone, which indicated that the DM could remove part of the humic acid-like substance and soluble microbial by-product-like material. Furthermore, the difference of the FRI percentage distribution of the three zones in the DMBR should contribute to the microorganisms with different functions under various DO circumstance.

\section{Conclusions}

The characteristics of DOM in the DMBR were investigated. Based on this study, the following conclusions could be drawn.

The effluent quality of the DMBR was excellent during the steady-state operation, and the removal efficiency of TP 

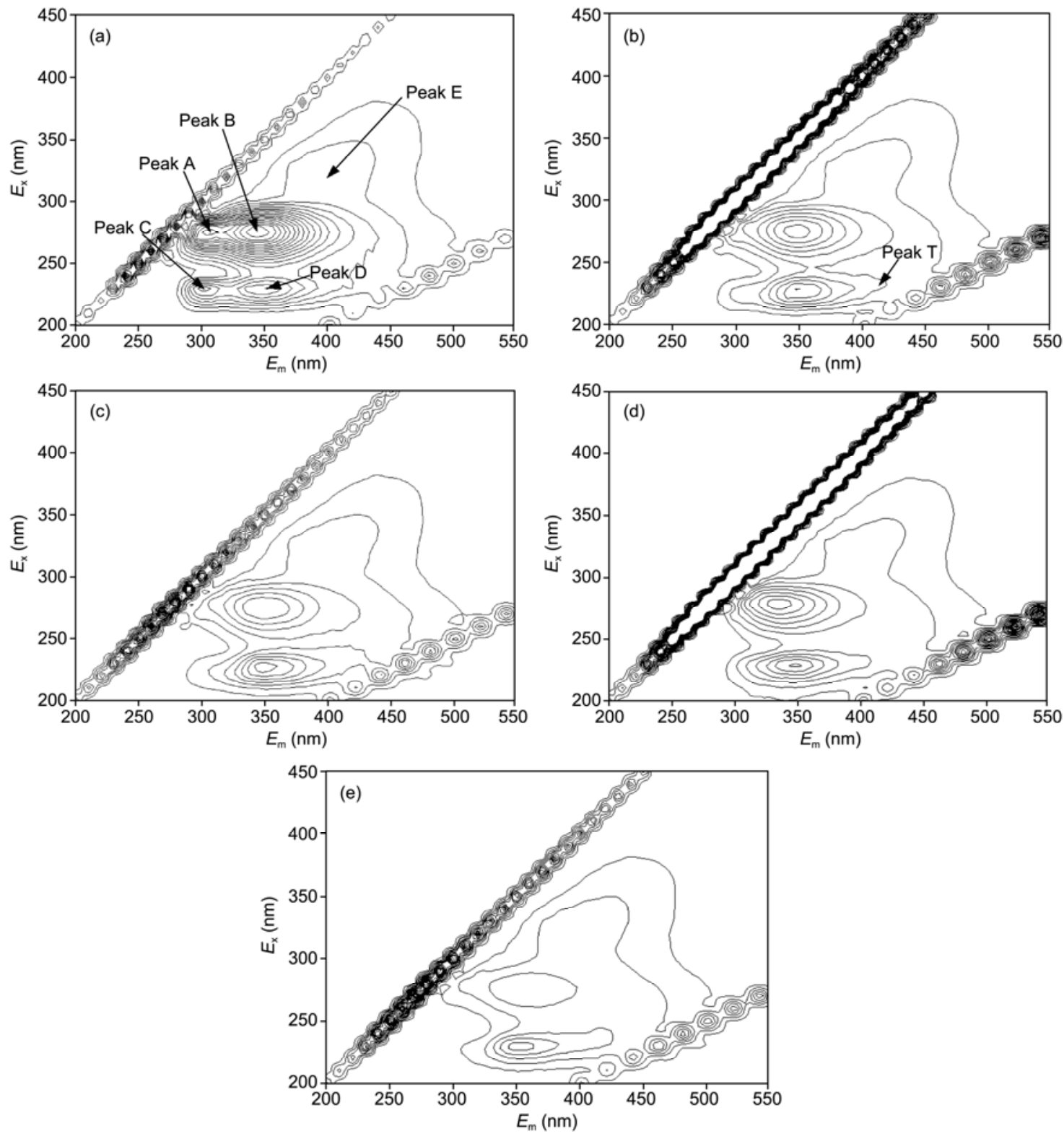

Figure 6 EEM spectra of (a) influent; (b) anaerobic zone; (c) anoxic zone; (d) aerobic zone; (e) effluent.

Table 2 Fluorescence spectral parameters of the influent, the effluent and the three zones in the DMBR ${ }^{\text {a) }}$

\begin{tabular}{|c|c|c|c|c|c|c|c|c|c|c|}
\hline \multirow{2}{*}{ Regions } & \multicolumn{2}{|c|}{ Influent } & \multicolumn{2}{|c|}{ Anaerobic zone } & \multicolumn{2}{|c|}{ Anoxic zone } & \multicolumn{2}{|c|}{ Aerobic zone } & \multicolumn{2}{|c|}{ Effluent zone } \\
\hline & $E_{\mathrm{x}} / E_{\mathrm{m}}$ & Intensity & $E_{\mathrm{x}} / E_{\mathrm{m}}$ & Intensity & $E_{\mathrm{x}} / E_{\mathrm{m}}$ & Intensity & $E_{\mathrm{x}} / E_{\mathrm{m}}$ & Intensity & $E_{\mathrm{x}} / E_{\mathrm{m}}$ & Intensity \\
\hline \multirow{2}{*}{ I, II } & $230 / 300$ & 225.2 & \multirow{2}{*}{$230 / 350$} & \multirow{2}{*}{209.2} & \multirow{2}{*}{$230 / 350$} & \multirow{2}{*}{227.1} & \multirow{2}{*}{$230 / 346$} & \multirow{2}{*}{224.3} & \multirow{2}{*}{$230 / 354$} & \multirow{2}{*}{177.0} \\
\hline & $230 / 352$ & 245.4 & & & & & & & & \\
\hline \multirow{2}{*}{ III } & \multirow{2}{*}{-} & \multirow{2}{*}{-} & \multirow{2}{*}{$240 / 422$} & \multirow{2}{*}{88.3} & $230 / 430$ & 96.4 & $230 / 428$ & 80.8 & \multirow{2}{*}{$240 / 418$} & \multirow{2}{*}{94.5} \\
\hline & & & & & $240 / 428$ & 92.0 & $240 / 424$ & 87.5 & & \\
\hline \multirow{3}{*}{ IV } & $270 / 300$ & 413.1 & $270 / 298$ & 114.0 & $270 / 298$ & 86.5 & $280 / 332$ & 259.6 & $270 / 348$ & 116.8 \\
\hline & $280 / 308$ & 405.2 & $270 / 348$ & 243.4 & $280 / 310$ & 116.8 & & & \multirow[t]{2}{*}{$280 / 310$} & \multirow[t]{2}{*}{89.4} \\
\hline & $280 / 344$ & 514.9 & $280 / 350$ & 242.4 & $280 / 348$ & 204.4 & & & & \\
\hline \multirow{2}{*}{ V } & \multirow{2}{*}{$320 / 396$} & \multirow{2}{*}{83.8} & $320 / 396$ & 78.1 & \multirow{2}{*}{$320 / 398$} & \multirow{2}{*}{81.6} & $320 / 398$ & 75.5 & \multirow{2}{*}{$320 / 400$} & \multirow{2}{*}{80.8} \\
\hline & & & $330 / 408$ & 77.8 & & & $330 / 400$ & 74.7 & & \\
\hline
\end{tabular}

a) Values are given merely the fluorescence intensity higher than 70 . 


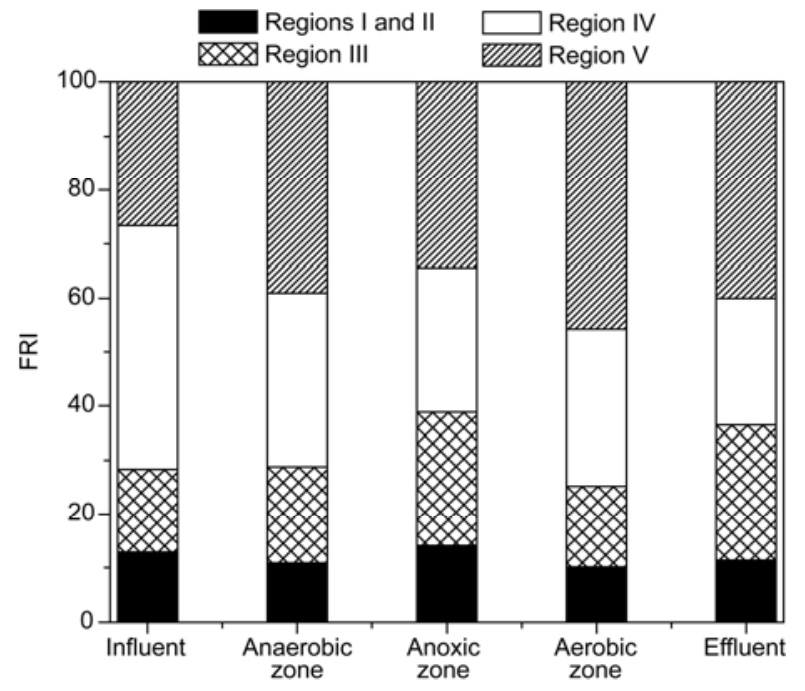

Figure 7 The bar graph of the FRI percentage distribution of the DOM samples in the DMBR.

reached to approximate $99 \%$ for synthetic wastewater. The increase of TMP for the DM could be divided into three stages.

The PS and PN concentration had opposite variation trends from the anaerobic zone to aerobic zone, and the DM rejected $70.2 \%$ proteins and $79.6 \%$ polysaccharides, respectively. The aerobic zone had a much broader MW distribution than the influent, and a small part of large molecules $(>10 \mathrm{kDa})$ could be rejected by DM in the filtration process.

The aromatic protein-like substance of the influent disappeared due to biodegradation. Two particular peaks of the effluent appeared in the anaerobic zone and anoxic zone illustrated that the DM closed to the stainless steel mesh might induce an anaerobic/anoxic micro environment. The redshift and/or blue-shift of fluorescence peaks with proteins and humic substances indicated the difference of compound structure in the DOM samples under the different operation circumstance in the DMBR.

This work was supported by the National Natural Science Foundation of China (51138009, 51208365, 20976139), the State Key Laboratory of Pollution Control and Resource Reuse, China (PCRRY11015), the National Key Technologies $R$ \& D Program (2012BAJ21B03), and the Project of the Science and Technology Commission of Shanghai Municipality (11dz1211202, 11QH1402600).

1 Anja D. Membrane fouling in membrane bioreactors-characterisation, contradictions, cause and cures. J Membr Sci, 2010, 363: 1-28

2 Dvorak L, Gomez M, Dvorakova M, et al. The impact of different operating conditions on membrane fouling and EPS production. Bioresource Technol, 2011, 102: 6870-6875

3 Kimura K, Yamato N, Yamamura H, et al. Membrane fouling in pilotscale membrane bioreactors (MBRs) treating municipal wastewater. Environ Sci Technol, 2005, 39: 6293-6299

4 Kuberkar V T, Davis R H. Modeling of fouling reduction by secondary membrane. J Membr Sci, 2000, 168: 243-258

5 Chu H Q, Cao D W, Jin W, et al. Characteristics of bio-diatomite dynamic membrane process for municipal wastewater treatment. J
Membr Sci, 2008, 325: 271-276

6 Ilani T, Schulz E, Chefetz B. Interactions of organic compounds with wastewater dissolved organic matter: Role of hydrophobic fractions. J Environ Qual, 2005, 34: 552-562

7 Imai A, Fukushima T, Matsushige K, et al. Characterization of dissolved organic matter in effluents from wastewater treatment plants. Water Res, 2002, 36: 859-870

8 Wang $\mathrm{Z} \mathrm{W}$, Wu Z C, Ying $\mathrm{X}$, et al. Membrane fouling in a submerged membrane bioreactor (MBR) under sub-critical flux operation: Membrane foulant and gel layer characterization. J Membr Sci, 2008, 325: 238-244

9 Wisniewski C, Grasmick A. Floc size distribution in a membrane bioreactor and consequences for membrane fouling. Colloid Surf A: Physicochem Eng Aspects, 1998, 138: 403-411

10 Bouhabila E, Ben Aim R, Buisson H. Fouling characterisation in membrane bioreactors. Sep Purif Technol, 2001, 22-23: 123-132

11 Lee W, Kang S, Shin H. Sludge characteristics and their contribution to microfiltration in submerged membrane bioreactor systems. J Membr Sci, 2003, 216: 217-227

12 Paul P, Hartung C. Modeling of biological fouling propensity by inference in a side stream membrane bioreactor. Desalination, 2008, 224: $154-159$

13 Rosenberger S, Evenblij H, Poele S T, et al. The importance of liquid phase analyses to understand fouling in membrane assisted activated sludge process-six case studies of different European research groups. J Membr Sci, 2005, 263: 113-126

14 Tang S J, Wang Z W, Wu Z C, et al. Role of dissolved organic matters $(\mathrm{DOM})$ in membrane fouling of membrane bioreactors for municipal wastewater treatment. J Hazard Mater, 2010, 178: 377-384

15 Liang S, Zhao Y, Liu C, et al. Effect of solution chemistry on the fouling potential of dissolved organic matter in membrane bioreactor systems. J Membr Sci, 2008, 310: 503-511

16 Liang S, Song L. Characteristics and fouling behaviours of dissolved organic matter in submerged membrane bioreactor systems. Environ Eng Sci, 2007, 24: 652-662

17 Dubois M, Gilles K A, Hamilton J K, et al. Calorimetric method for determination of sugars and related substances. Anal Chem, 1956, 28 : 350-356

18 Hartree E F. Determination of protein: A modification of the Lowry method that gives linear photometric response. Anal Biochem, 1972, 48: 422-427

19 Chinese NEPA. Water and Wastewater Monitoring Methods. 3rd ed. Beijing: Chinese Environmental Science Publishing House, 1997

20 Monclus H, Sipma J, Ferrero G, et al. Biological nutrient removal in an MBR treating municipal wastewater with special focus on biological phosphorus removal. Bioresour Technol, 2010, 101: 3984-3991

21 Ognier S, Wisniewski C, Grasmick A. Membrane bioreactor fouling in sub-critical filtration conditions: A local critical flux concept. J Membr Sci, 2004, 229: 171-177

22 Cho B D, Fane A G. Fouling transients in nominally sub-critical flux operation of a membrane bioreactor. J Membr Sci, 2002, 209: 391403

23 Hwang B K, Lee W N, Yeon K M, et al. Correlating TMP increases with microbial characteristics in the bio-cake on the membrane surface in a membrane bioreactor. Environ Sci Technol, 2008, 42: 39633968

24 Zhang J, Chua H C, Zhou J, et al. Factors affecting the membrane performance in submerged membrane bioreactors. J Membr Sci, 2006, 284: 54-66

25 Cao D W, Chu H Q, Jin W, et al. Characteristics of the biodiatomite dynamic membrane (cake layer) for municipal wastewater treatment. Desalination, 2010, 250: 544-547

26 Frølund B, Palmgren R, Keiding K, et al. Extraction of extracellular polymers from activated sludge using a cation-exchange resin. Water Res, 1996, 30: 1749-1758

27 Pan J R, Su Y C, Huang C P. Characteristics of soluble microbial products in membrane bioreactor and its effect on membrane fouling. Desalination, 2010, 250: 778-780

28 Meng F G, Zhang H M, Yang F L, et al. Effect of filamentous bacte- 
ria on membrane fouling in submerged membrane bioreactor. $\mathrm{J}$ Membr Sci, 2006, 272: 161-168

29 Malamis S, Andreadakis A. Fractionation of proteins and carbohydrates of extracellular polymeric substances in a membrane bioreactor system. Bioresour Technol, 2009,100: 3350-3357

30 Brookes A, Jefferson B, Guglielmi G, et al. Sustainable flux fouling in a membrane bioreactor: Impact of flux and MLSS. Sep Purif Technol, 2006, 41: 1279-1291

31 Drews A, Lee C H, Kraume M. Membrane fouling-A review on the role of EPS. Desalination, 2006, 200: 186-188

32 Evenblij H, van der Graaf J H J M. Occurrence of EPS in activated sludge from a membrane bioreactor treating municipal wastewater. Water Sci Technol, 2004, 50: 293-300

33 Drews A, Mante J, Iversen V, et al. Impact of ambient conditions on SMP elimination and rejection in MBRs. Water Res, 2007, 41: 38503858

34 Meng F G, Zhou Z B, Ni B J, et al. Characterization of the size-fractionated biomacromolecules: Tracking their role and fate in a membrane bioreactor. Water Res, 2011, 45: 4661-4671

35 Ni B J, Rittmann B E, Fang F, et al. Long-term formation of microbial products in a sequencing batch reactor. Water Res, 2010, 44: 3787-3796

36 Rosenberger S, Laabs C, Lesjean B, et al. Impact of colloidal and soluble organic material on membrane performance in membrane bioreactors for municipal wastewater treatment. Water Res, 2006, 40: 710-720

37 Seo D H, Kim Y J, Ham S Y, et al. Characterization of dissolved organic matter in leachate discharged from final disposal sites which contained municipal solid waste incineration residues. J Hazard Ma- ter, 2007, 148: 679-692

38 Chow C W K, Fabris R, Van Leeuwen J , et al. Assessing natural organic matter treatability using high performance size exclusion chromatography. Environ Sci Technol, 2008, 42: 6683-6689

39 Song L F, Liang S, Yuan L Y. Retarded transport and accumulation of soluble microbial products in a membrane bioreactor. J Environ Eng, 2007, 133: 36-43

40 Meng F G, Drews A, Mehrez R, et al. Occurrence, source, and fate of dissolved organic matter (DOM) in a pilot-scale membrane bioreactor. Environ Sci Technol, 2009, 43: 8821-8826

41 Liang S, Liu C, Song L. Soluble microbial products in membrane bioreactor operation: Behaviors, characteristics, and fouling potential. Water Res, 2007, 41: 95-101

42 Chen W, Westerhoff P, Leenheer J A, et al. Fluorescence excitationemission matrix regional integration to quantify spectra for dissolved organic matter. Environ Sci Technol, 2003, 37: 5701-5710

43 Wang Z W, Wu Z C, Tang S J. Characterization of dissolved organic matter in a submerged membrane bioreactor by using three-dimensional excitation and emission matrix fluorescence spectroscopy. Water Res, 2009, 43: 1533-1540

44 Sheng G P, Yu H Q. Characterization of extracellular polymeric substances of aerobic and anaerobic sludge using three-dimensional excitation and emission matrix fluorescence spectroscopy. Water Res, 2006, 40: 1233-1239

45 Liu T, Chen Z L, Yu W Z, et al. Characterization of organic membrane foulants in a submerged membrane bioreactor with pre-ozonation using three-dimensional excitation-emission matrix fluorescence spectroscopy. Water Res, 2011, 45: 2111-2121

Open Access This article is distributed under the terms of the Creative Commons Attribution License which permits any use, distribution, and reproduction in any medium, provided the original author(s) and source are credited. 